\title{
Iron deficiency in non-anemic chronic obstructive pulmonary disease in a predominantly male population: An ignored entity
}

\author{
Vidushi Rathi ${ }^{1}$, Pranav Ish ${ }^{1}$, Gulvir Singh ${ }^{2}$, Mani Tiwari², Nitin Goel ${ }^{2}$, Shailendra Nath Gaur ${ }^{2}$ \\ ${ }^{1}$ Department of Pulmonary, Critical Care and Sleep Medicine, Vardhman Mahavir Medical College and Safdarjung \\ Hospital, New Delhi; ${ }^{2}$ Department of Pulmonary Medicine, Vallabhbhai Patel Chest Institute, New Delhi, India
}

\begin{abstract}
Non-anemic iron deficiency has been studied in heart failure, but studies are lacking in chronic obstructive pulmonary disease (COPD). The potential clinical implications of association of iron deficiency with the severity of COPD warrant research in this direction. This was an observational, cross-sectional study on patients with COPD to compare disease severity, functional status and quality of life in non-anemic patients with COPD between two groups - iron deficient and non-iron deficient. Stable nonanemic COPD with no cause of bleeding were evaluated for serum iron levels, ferritin levels, TIBC, 6MWD, SGRQ,
\end{abstract}

Correspondence: Shailendra Nath Gaur, Department of Pulmonary Medicine, Vallabhbhai Patel Chest Institute, New Delhi, India. Tel. +91.9811271916. E-mail: sngaur@yahoo.com

Key words: COPD; iron deficiency; non-anemic.

Conflict of interest: The Authors declare no conflict of interest relating to the study.

Ethics approval and consent to participate: the study received the Institutional Ethics Committee approval.

Informed consent: obtained.

Contributions: All the authors made a substantive intellectual contribution to study design, data acquisition, analysis or interpretation, manuscript drafting and/or revising. All the authors have read and approved the final version of the manuscript and agreed to be accountable for all aspects of the work in ensuring that questions related to the accuracy or integrity of any part of the work are appropriately investigated and resolved.

Received for publication: 4 July 2019.

Accepted for publication: 7 January 2020.

${ }^{\circ}$ Copyright: the Author(s), 2020

Licensee PAGEPress, Italy

Monaldi Archives for Chest Disease 2020; 90:1126

doi: 10.4081/monaldi.2020.1126

This article is distributed under the terms of the Creative Commons Attribution Noncommercial License (by-nc 4.0) which permits any noncommercial use, distribution, and reproduction in any medium, provided the original author(s) and source are credited. spirometry, and CAT questionnaire. The study patients were divided into iron replete (IR) and iron deficient (ID) groups. A total of 79 patients were studied, out of which 72 were men and seven were women. The mean age was $61.5 \pm 8.42$ years. Of these, 36 (45.5\%; 95\% CI, 34.3-56.8\%) had iron deficiency. Mean 6minute-walk distance was significantly shorter in ID (354.28 \pm 82.4 meters $v s 432.5 \pm 47.21$ meters; $\mathrm{p}=0.001)$. A number of exacerbations in a year were more in ID group ( $p=0.003)$, and more patients in ID had at least two exacerbations of COPD within a year $(\mathrm{p}=0.001)$. However, the resting $\mathrm{pO}_{2}, \mathrm{SaO}_{2}$, and $\mathrm{SpO}_{2}$ levels did not differ significantly between the two groups ( $\mathrm{p}=0.15$ and $\mathrm{p}=0.52$, respectively). Also, there was no significant difference in the distribution of patients of a different class of airflow limitations between the two groups. Non-anemic iron deficiency (NAID) is an ignored, yet easily correctable comorbidity in COPD. Patients with iron deficiency have a more severe grade of COPD, had lesser exercise capacity and more exacerbations in a year as compared to non-iron deficient patients. So, foraying into the avenue of iron supplementation, which has shown promising results in improving functional capacity in heart failure and pulmonary hypertension, may well lead to revolutionary changes in the treatment of COPD.

\section{Introduction}

Chronic obstructive pulmonary disease (COPD) is a major cause of morbidity and mortality worldwide [1]. It is a leading cause of death globally and accounts for about half a million deaths in India annually [2]. In the natural history of COPD, comorbidities greatly influence the morbidity, economic burden, and mortality. COPD is associated with various comorbidities such as cardiovascular disease, diabetes, pneumonia, weight loss, anemia, etc., all of which have a deleterious effect on the disease [3]. Screening of the comorbidities should be an important component in the management of a COPD patient.

Even in the absence of anemia, deficiency of iron has been revealed to be important comorbidity in chronic heart failure (CHF) and pulmonary arterial hypertension (PAH) [4-6]. Iron deficiency is now known to be a complication of chronic diseases (e.g., inflammatory bowel disease, Parkinson's disease, rheumatoid disease, chronic renal failure), regardless of associated anemia [6]. Iron deficiency and non-anemic iron deficiency (NAID) in patients with COPD has been a poorly explored arena. The possible clinical implications of association of iron deficiency with the severity of COPD warrant research in this direction. The present study aims to find out the presence of NAID in patients with COPD and its correlation with the severity of the disease. 


\section{Patients and Methods}

We aimed to compare disease severity, functional status and quality of life in non-anemic patients with COPD between two groups: iron deficient and non-iron deficient.

This was an observational, cross-sectional study on patients with COPD attending the out-patient clinics at a tertiary care center in New Delhi, India. The study was carried out after approval of the Institutional Ethics Committee. Written informed consent was obtained from all the subjects before induction in the study.

\section{Inclusion and exclusion criteria}

Patients diagnosed with COPD according to Global Initiative for Chronic Obstructive Lung Disease (GOLD) [1] criterion, who had not had any exacerbation or hospital admission in the four preceding weeks and were found to be non-anemic were included in the study. Anemia was defined according to the world health organisation ${ }^{7}$ as hemoglobin $(\mathrm{Hb})<13 \mathrm{~g} / \mathrm{dl}$ for males and $\mathrm{Hb}<12 \mathrm{~g} / \mathrm{dl}$ for females. Pregnant and lactating females, patients on treatment for anemia, patients with suspected blood loss and malignancies were excluded from the study. The rest were enrolled in the study.

Detailed medical history and physical examination were performed by a respiratory physician. Hematological and spirometry measurements included the following: i) Iron studies: serum iron and TIBC were estimated by ferrozine method. Serum ferritin was measured by chemiluminescence method. ii) Pulmonary function testing- dry, rolling-seal spirometer of the Benchmark model lung function machine (P.K. Morgan, Kent, UK) with prediction equations for north Indian adults [8]. iii) Forced vital capacity (FVC), forced expiratory volume in $1^{\text {st }} \mathrm{S}\left(\mathrm{FEV}_{1}\right)$; and, $\mathrm{FEV}_{1} / \mathrm{FVC}$ ratio was measured resting arterial blood gas analysis (ABL800FLEX blood gas analyzer). iv) Six-minute walking test performed in accordance with ATS guidelines [9]. v) Saint George's Respiratory Questionnaire (validated Hindi version) [10,11]. vi) COPD Assessment Test (CAT)-Hindi version [12].

The WHO has suggested $15 \mathrm{mcg} / \mathrm{l}$ as a cut-off for ferritin. However, in the absence of a diagnostic bone marrow examination, no current laboratory test can confidently rule out iron deficiency. Recent studies correlating the presence or absence of stainable iron with serum ferritin in normal individuals and in patients, and also patients with anemia responsive to iron therapy, indicate that low threshold level of ferritin had only a sensitivity of $25 \%$ for detecting iron deficiency. The sensitivity could be improved to $92 \%$, with a positive predictive value of $83 \%$, by using a diagnostic cut off value of $30 \mathrm{ng} / \mathrm{ml}$. Hence, a cut off of $30 \mathrm{ng} / \mathrm{ml}$ was used in his study. Besides, as ferritin can behave as an acute phase reactant with unreliable values, so the presence of either ferritin $<30 \mathrm{ng} / \mathrm{ml}$ or transferrin saturation $<20 \%$ was used to diagnose iron deficiency $[13,14]$. Given this, patients were divided into two groups: iron deficient (ID) and non-iron deficient (NID) and were compared on various parameters mentioned above.

\section{Statistical analysis}

It was estimated that a sample of 68 patients would be needed to demonstrate a $20 \%$ prevalence of iron deficiency with $90 \%$ confidence and $8 \%$ precision, assuming an effectively unlimited population [15]. Taking a drop-out rate of $5 \%$, the required sample size required was found to be 72 .

Data were summarized with the mean and median as measures of central tendency and standard deviations and interquartile ranges as measures of spread for continuous variables. Frequencies were taken as categorical variables. Categorical variables were reported as numbers and percentages and were compared using the $\chi^{2}$ test or Fisher exact test. Continuous variables were reported as the mean (standard deviation) or median (interquartile range) as appropriate, and these variables were compared using the $t$-test or the MannWhitney test. All tests were 2-sided, and p less than 0.05 was considered statistically significant.

\section{Results}

A total of 79 patients were studied, out of which 72 were men and seven women. Thus, the study was carried out in a predominantly male population. The mean age was $61.5 \pm 8.42$ years. Of these, 36 (45.5\%; 95\% CI, 34.3-56.8\%) had iron deficiency. Patients were older in NID vs ID group (mean age 63.9 vs 58.7). The two groups formed, NID and ID were similar and quite comparable regarding their baseline parameters of height, weight, BMI, smoking status with only difference seen in age. The serum ferritin, percent transferrin saturation and serum iron in ID group was significantly lower and total iron binding capacity were significantly higher. The hemoglobin levels ranged between 12-17 $\mathrm{g} / \mathrm{dl}$ with a significantly lower level in the ID group. The median (IQR) ferritin concentration was 63 (42-103) mcg/l; range 6-284 $\mathrm{mcg} / \mathrm{l})$ (Table 1) Patients with iron deficiency had lower hemoglobin (13.86 \pm 0.93 vs $14.79 \pm 1.08 ; \mathrm{p}=0.001)$ and lower hematocrit (42.61 \pm 4.07 vs 45.16 $\pm 3.21 ; \mathrm{p}=0.002)$. However, mean corpuscular volume (MCV), mean corpuscular hemoglobin concentration (MCHC) and white cell counts did not differ according to iron status in COPD patients.

On evaluating the effects of this iron deficiency, the mean 6minute walk distance (6MWD) was significantly shorter in ID (354.28 \pm 82.4 meters $v s 432.5 \pm 47.21$ meters; $\mathrm{p}=0.001)$. A number of exacerbations in a year were more in ID group ( $p=0.003$ ), and more patients in ID had at least two exacerbations of COPD within a year $(\mathrm{p}=0.001)$ (Table 2). The resting $\mathrm{pO}_{2}, \mathrm{SaO}_{2}$, and $\mathrm{SpO}_{2}$ levels were found not to differ significantly between the two groups ( $\mathrm{p}=0.15$ and $\mathrm{p}=0.52$, respectively). Most of the patients $(76 \%)$ belonged to the moderate and severe class of airflow limitation (GOLD 2 and 3), $12 \%$ belonged to very severe category (GOLD 4 ) while only $5 \%$ could be classified as mild airflow limitation (GOLD 1). There was no significant difference in the distribution of patients of a different class of airflow limitations between the two groups. There was also no significant difference in FVC (\% predicted) $[84.32 \%(17.24) v s$ $84.97 \%(18.79)(\mathrm{p}=0.87)]$ and $\mathrm{FEV}_{1}$ (\% predicted) $[53.41 \%(18.72)$ vs $47.61 \%(15.5)(\mathrm{p}=0.14)]$ in NID vs ID.

Iron deficiency did not significantly impact SGRQ total score $(p=0.11)$, activity $(0.25)$ and impact scores $(0.31)$ however, ID patients had higher SGRQ symptom score $(61.41 \pm 18.95$ vs $47.69 \pm 21.30 ; \mathrm{p}=0.003)$. The CAT scores of the ID group although higher was not found to be statistically significant $(23.00 \pm 6.45 \mathrm{vs}$ $19.88 \pm 8.23 ; \mathrm{p}=0.06)$.

In the ID group, $2(5.6 \%), 11(30.6 \%)$ and $23(63.9 \%)$ patients belonged to GOLD group A, B and D respectively compared to 8 (18.6\%), $25(58.1 \%)$ and $10(23.3 \%)$ patients in NID group. So, patients in GOLD category D in ID vs NID was $63.9 \%$ vs $23.3 \%$ in IR group $(\mathrm{p}<0.001)$, classified according to GOLD 2019 [1]. 


\section{Discussion}

Evaluation of iron deficiency in COPD is an under-researched area, particularly so in patients who do not display overt anemia. The main findings of our study were that there is a high prevalence of iron deficiency in non-anemic patients with COPD. Such patients had poor functional status as evidenced by lower 6-minute walk distance, a greater number of acute exacerbations in the previous year, and worse GOLD COPD assessment grade. We, however, found no significant difference regarding hypoxia, airflow limitation or quality of life in patients with and without iron deficiency.

Interestingly, patients in the ID group had significantly lower hemoglobin compared to those in NID despite all patients taken being non-anemic according to WHO standards. Considering that iron is a crucial element in hemoglobin synthesis, this difference may imply affected erythropoiesis. It is indeed possible that these patients may have developed overt anemia down the line. The hematocrit was also lower in these patients. Lower hematocrit is an important predictor of mortality as depicted by Chambellan et al.

Table 1. Demographic and clinical characteristics of patients.

\begin{tabular}{|c|c|c|c|c|}
\hline Characteristic & $\begin{array}{c}\text { All patients } \\
(\mathrm{n}=79)\end{array}$ & $\begin{array}{l}\text { Non-iron deficient (NID) } \\
(\mathrm{n}=43)\end{array}$ & $\begin{array}{l}\text { Iron deficient(ID) } \\
(\mathrm{n}=36)\end{array}$ & p \\
\hline Age (years) & $61.56(8.42)$ & $63.93(1.25)$ & $58.75(1.31)$ & 0.005 \\
\hline Sex, male & $72(89.87)$ & 41 & 31 & 0.24 \\
\hline Height (meters) & $162(8.85)$ & $161.86(5.62)$ & $162.19(8.16)$ & 0.83 \\
\hline Weight (kg) & $59.12(12.57)$ & $59.86(12.32)$ & $58.25(12.98)$ & 0.57 \\
\hline BMI $\left(\mathrm{kg} / \mathrm{m}^{2}\right)$ & $22.52(4.27)$ & $22.86(4.13)$ & $22.09(4.46)$ & 0.44 \\
\hline Smoking pack years & $20(10-40)$ & $20(10-30)$ & $22(10-40)$ & 0.52 \\
\hline $\mathrm{Hb}(\mathrm{g} / \mathrm{dl})$ & $14.36(1.11)$ & $14.79(1.08)$ & $13.86(0.93)$ & 0.001 \\
\hline Hct (\%) & $44(3.82)$ & $45.16(3.21)$ & $42.61(4.07)$ & 0.002 \\
\hline $\mathrm{ESR}(\mathrm{mm})$ & $19(10-25)$ & $16(8-20)$ & $20(12-27)$ & 0.021 \\
\hline Ferritin (mcg/l) & $63(42-104)$ & $75(59-113)$ & $52(20-97)$ & 0.003 \\
\hline $\mathrm{TIBC}(\mu \mathrm{g} / \mathrm{dl})$ & $340(300-383)$ & $324(295-345)$ & $367(316-406)$ & 0.001 \\
\hline Transferrin saturation (\%) & $21(15-29)$ & $28(22-31)$ & $14.5(10-17.5)$ & 0.001 \\
\hline $\mathrm{Fe}(\mu \mathrm{g} / \mathrm{dl})$ & $70(52-94)$ & $88(76-99)$ & $52(37-62)$ & 0.001 \\
\hline
\end{tabular}

BMI, body mass index; Hb, Hemoglobin; Hct, hematocrit; ESR, erythrocyte sedimentation rate; TIBC, total iron binding capacity; Fe, Serum iron. Values represent numbers of patients or medians (interquartile range) or means (SD), as appropriate.

Table 2. Comparison of functional status, spirometry and arterial blood gas parameters in non-iron deficient (NID) and iron deficient (ID) groups.

\begin{tabular}{|c|c|c|c|}
\hline Characteristic & NID $(n=43)$ & ID $(n=36)$ & p \\
\hline 6MWD (m) & $432.5(47.21)$ & $354.28(82.40)$ & 0.001 \\
\hline SGRQ, symptoms score & $47.69(21.30)$ & $61.41(18.95)$ & 0.003 \\
\hline SGRQ, total score & $43.93(16.50)$ & $50.75(21.51)$ & 0.11 \\
\hline FEV1 (\% predicted) & $53.41(18.72)$ & $47.61(15.5)$ & 0.14 \\
\hline Patients in GOLD group D & $10(23.3 \%)$ & $23(63.9 \%)$ & $<0.001$ \\
\hline $\mathrm{PaO}_{2}(\mathrm{~mm} \mathrm{Hg})$ & $77.16(8.48)$ & $76.16(10.94)$ & 0.65 \\
\hline $\mathrm{PaCO}_{2}(\mathrm{~mm} \mathrm{Hg})$ & $39.37(6.29)$ & $41.86(6.94)$ & 0.09 \\
\hline $\mathrm{SaO}_{2}(\%)$ & $95.72(3.09)$ & $94.58(4.01)$ & 0.15 \\
\hline $\mathrm{SpO}_{2}$ & $95.88(3.23)$ & $95.38(3.72)$ & 0.52 \\
\hline \multicolumn{4}{|l|}{ Exacerbation in a year } \\
\hline $\begin{array}{l}0 \\
1 \\
2 \\
3 \\
4 \\
5\end{array}$ & $\begin{array}{c}13 \\
21 \\
4 \\
3 \\
2 \\
0\end{array}$ & $\begin{array}{c}2 \\
11 \\
7 \\
8 \\
6 \\
2\end{array}$ & 0.003 \\
\hline$\geq 2$ Exacerbations in a year & $9(28.1 \%)$ & $23(71.9 \%)$ & 0.001 \\
\hline
\end{tabular}

6MWD, 6-minute walk distance; SGRQ, St. George's Respiratory Questionnaire; FEV1, forced expiratory volume in the $1^{\text {st }}$ s; GOLD, Global Initiative for Chronic Obstructive Lung Disease; PaO ${ }_{2}$, partial pressure of oxygen in arterial blood; $\mathrm{PaCO}_{2}$, partial pressure of carbon dioxide in arterial blood; $\mathrm{SaO}_{2}$, arterial saturation; $\mathrm{SpO}_{2}$, peripheral capillary oxygen saturation. 
[16], who showed that the relative risk of death decreased by $14 \%$ with every $5 \%$ increase in hematocrit and that hematocrit was the strongest predictor of mortality next to age.

In ID group, patients had a significantly shorter 6MWD. The 6MWT was chosen over other functional exercise capacity tests since most of the activities of daily living are performed at submaximal levels of exertion and hence the 6MWD may be better at revealing the functional exercise level of patients for daily physical activities [17]. Exercise capacity is dependent on tissue oxidative and oxygen carrying capacity and iron status affects both of these. This tissue oxidative capacity determines the endurance and submaximal exertion and is impaired proportional to iron deficiency. The oxygen carrying capacity, on the other hand, is impaired only in severe iron deficiency when erythropoiesis is also significantly affected [18]. This is in line with previous studies where iron deficiency both with and without anemia have been associated with poor exercise capacity in COPD [19,20]. The quality of life of patients as assessed by SGRQ scores was not significantly different. However, the SGRQ total score and its components, symptom, activity and impact scores, were all more than 4 points higher in the ID group, which is considered the minimum clinically important difference [12].

Patients in the ID group had a significantly greater number of acute exacerbations in the past year as compared to their NID counterparts. Exacerbations contribute to COPD progression and strongly predict the outcome. Past exacerbations are considered to be the single most important risk factor for future exacerbations which in turn strongly affects prognosis $[21,22]$. This strong association of iron deficiency with acute exacerbations can have important clinical implications in the treatment of COPD as prevention of exacerbations forms a cornerstone in the management of the disease.

Our findings draw parallels from studies done in other chronic diseases such as heart failure and pulmonary hypertension that have also shown a high prevalence of NAID [4,5] and the few studies done in COPD $[19,23,24]$. There is no unanimity on the definition of iron deficiency in patients with COPD. While a recent study had taken stricter criteria [23], other studies [19,25] have chosen the usual criteria of ferritin less than $100 \mathrm{mcg}$ as used in studies of iron deficiency in heart failure and pulmonary hypertension. We used the cut-off of ferritin less than $30 \mathrm{mcg}$ or transferrin saturation less than $20 \%$ to increase the sensitivity as none of the cut-offs are adequately validated [13]

The crux of this study is that iron deficiency is found to be associated with more exacerbations and poor functional capacity. Foraying into the avenue of iron supplementation, which has shown promising results in improving functional capacity in heart failure and pulmonary hypertension, may well lead to revolutionary changes in the treatment of COPD. While we agree that robust, unequivocal data regarding the benefit of iron supplementation in heart failure is lacking [26], it still deserves a due consideration in patients with COPD also.

\section{Conclusions}

We conclude that patients with iron deficiency have a more severe grade of COPD, lesser exercise capacity and more exacerbations in a year as compared to non-iron deficient patients. We, however, could not find any significant difference in their airflow limitation and overall quality of life. Thus, our study suggests that NAID is associated with more severe COPD with a higher risk of exacerbations which is in turn associated with poorer prognosis, and should therefore not be ignored.

\section{Strengths and limitations}

To our knowledge, this study was the first of its kind in India where iron deficiency was investigated in COPD patients without overt anemia. Patients' clinical course, quality of life and functional status were all assessed and compared between the two groups. This study has brought to focus the need to consider iron deficiency as a possible poor prognostic marker in patients with COPD.

The potential limitations of our study also deserve comment. As this was a study based in a tertiary care hospital most of our patients were moderate to severe category of COPD and thus might not be reflective of the general population. Our sample size was small, and data from larger studies are needed to further validate our findings. We did not have a control arm (non-COPD), so we could not comment whether an iron deficiency in non-anemic COPD patients was more common than in general population. $\mathrm{C}$ reactive protein estimation and correlation with iron deficiency was not carried out. Notwithstanding the limitations, the current study made an earnest attempt to address issues of potential interest in patients with COPD and brought to light a significant, possibly treatable comorbidity that was hiding in plain sight.

We suggest a study with larger number of participants to evaluate role of iron deficiency in COPD and a possible role of iron supplementation.

\section{References}

1. Global Initiative for Chronic Obstructive Lung Disease (GOLD). Global strategy for the diagnosis, management, and prevention of chronic obstructive pulmonary disease. 2019 report. Available from: https://goldcopd.org/wp-content/uploads/2018/11/GOLD2019-v1.7-FINAL-14Nov2018-WMS.pdf

2. Salvi S, Agrawal A. India needs a national COPD prevention and control programme. J Assoc Physicians India 2012;60:5-7.

3. Barnes PJ, Celli BR. Systemic manifestations and comorbidities of COPD. Eur Respir J 2009;33:1165-85.

4. Yeo TJ, Yeo PS, Wong R C-C, et al. Iron deficiency in a multiethnic Asian population with and without heart failure: prevalence, clinical correlates, functional significance and prognosis. Eur J Heart Fail 2014;16:1125-32.

5. Ruiter G, Lankhorst S, Boonstra A, et al. Iron deficiency is common in idiopathic pulmonary arterial hypertension. Eur Respir J 2011;37:1386-91

6. Jankowska EA, Rozentryt P, Witkowska A, et al. Iron deficiency: an ominous sign in patients with systolic chronic heart failure. Eur Heart J 2010;31:1872-80.

7. WHO. Haemoglobin concentrations for the diagnosis of anaemia and assessment of severity. Accessed On: 1 June 2019. Available from: http://www.who.int/vmnis/indicators/haemoglobin/en/ index.html

8. Chhabra SK, Kumar R, Gupta U, et al. Prediction equations for spirometry in adults from northern India. Indian J Chest Dis Allied Sci 2014;56:221-9. Erratum in: Indian J Chest Dis Allied Sci 2015;57:204.

9. ATS committee on proficiency standards for clinical pulmonary function laboratories. ATS Statement: Guidelines for the six 
minute walk test. Am J Respir Crit Care Med 2002;166:111-7.

10. $\mathrm{Xu} \mathrm{W,} \mathrm{Collet} \mathrm{JP,} \mathrm{Shapiro} \mathrm{S,} \mathrm{et} \mathrm{al.} \mathrm{Validation} \mathrm{and} \mathrm{clinical}$ interpretation of the St George's Respiratory Questionnaire among COPD patients, China. Int J Tuberc Lung Dis 2009;13:181-9.

11. Jones PW. St. George's Respiratory Questionnaire: MCID. COPD 2005;2:75-9.

12. Jones PW, Harding G, Berry P, et al. Development and first validation of the COPD Assessment Test. Eur Respir J 2009;34:648-54.

13. Goodnough LT, Nemeth E, Ganz T. Detection, evaluation, and management of iron-restricted erythropoiesis. Blood 2010;116: 4754-61

14. Okonko DO, Grzeslo A, Witkowski T, et al. Effect of intravenous iron sucrose on exercise tolerance in anemic and nonanemic patients with symptomatic chronic heart failure and iron deficiency FERRIC-HF: a randomized, controlled, observer-blinded trial. J Am Coll Cardiol 2008;51:103-12.

15. Dean AG, Sullivan KM, Soe MM. OpenEpi: Open source epidemiologic statistics for public health. Accessed on: 6 May 2019. Available from: www.OpenEpi.com.

16. Chambellan A, Chailleux E, Similowski T, ANTADIR Observatory Group. Prognostic value of the hematocrit in patients with severe COPD receiving long-term oxygen therapy. Chest 2005;128:1201-8.

17. Wise RA, Brown CD. Minimal clinically important differences in the six-minute walk test and the incremental shuttle walking test. COPD 2005;2:125-9.

18. Haas JD, Brownlie T 4th. Iron deficiency and reduced work capacity: a critical review of the research to determine a causal relationship. J Nutr 2001;131:S676-88. Siscussion S688-90S.

19. Barberan-Garcia A, Rodríguez DA, Blanco I, et al. Nonanaemic iron deficiency impairs response to pulmonary rehabilitation in COPD. Respirology 2015;20:1089-95.

20. Cote C, Zilberberg MD, Mody SH, et al. Haemoglobin level and its clinical impact in a cohort of patients with COPD. Eur Respir J 2007;29:923-9.

21. Hurst JR, Vestbo J, Anzueto A, et al. Susceptibility to exacerbation in chronic obstructive pulmonary disease. N Engl J Med 2010;363:1128-38.

22. Halpin DM, Decramer M, Celli B, et al. Exacerbation frequency and course of COPD. Int J Chron Obstruct Pulmon Dis 2012;7:653-61.

23. Nickol AH, Frise MC, Cheng HY, et al. A cross-sectional study of the prevalence and associations of iron deficiency in a cohort of patients with chronic obstructive pulmonary disease. BMJ Open 2015;5:e007911.

24. Plesner LL, Schoos MM, Dalsgaard M, et al. Iron deficiency in COPD associates with increased pulmonary artery pressure estimated by echocardiography. Heart Lung Circ 2017;26:101-4.

25. Silerberg DS, Mor R, Weu MT, et al. Anemia and iron deficiency in COPD patients: prevalence and the effects of correction of the anemia with erythropoiesis stimulating agents and intravenous iron. BMC Pulm Med 2014;14:24 .

26. Anker SD, Comin Colet J, Filippatos G, et al. Ferric carboxymaltose in patients with heart failure and iron deficiency. N Engl J Med 2009;361:2436-48. 